\title{
Um seminário dispositivo: a humanização do Sistema Único de Saúde (SUS) em debate
}

Ana Lúcia Coelho Heckert ${ }^{1}$ Eduardo Passos ${ }^{2}$

Maria Elizabeth Barros de Barros ${ }^{3}$

HECKERT, A.L.C.; PASSOS, E.; BARROS, M.E.B. An instrumental seminar: humanization of the Brazilian Unified Health System (SUS) under discussion. Interface - Comunic., Saude, Educ., v.13, supl.1, p.493-502, 2009.

This paper discusses the process of constructing the seminar "SUS Humanization under Discussion" and demonstrates its connection with the current challenges of the Brazilian Unified Health System (SUS) and with the propositions of the National Humanization Policy (PNH). It presents the principles and guidelines of the $\mathrm{PNH}$ for SUS and its construction process, and discusses the different meanings of the term "humanization". It concludes by indicating the methodological stakes of the seminar, which aimed to promote a wide debate about the humanization of SUS by means of circles of conversation. These had the objective of forming an interface with professionals who are engaged in training workers for SUS and who are responsible for producing knowledge in the field of healthcare and for training students in this field.

Keywords: Humanization of assistance. Healthcare. Training. Health System.
O artigo discute o processo de construção do seminário "Humanização do SUS em Debate" indicando sua conexão com os desafios atuais do SUS e com as proposições da Política Nacional de Humanização (PNH). Apresenta os princípios e diretrizes da Política Nacional de Humanização do SUS e seu processo de construção, discutindo os diversos sentidos do termo humanização. Ao final é indicada a aposta metodológica do seminário que se destinou a promover um amplo debate sobre a humanização do SUS, por meio de rodas de conversação que objetivavam a interface com profissionais que atuam na formação dos trabalhadores do SUS, responsáveis pela produção de conhecimento na área da saúde e pela formação dos acadêmicos neste campo.

Palavras-chave: Humanização da assistência. Saúde. Formação. Sistema Único de Saúde.
${ }^{1}$ Departamento de Psicologia, Universidade Federal do Espírito Santo (Ufes). Rua Moacir Avidos, 63/401-B, Praia do Canto. Vitória, ES, Brasil. 29.055-350 ana.heckert@gmail.com ${ }^{2}$ Departamento de Psicologia, Universidade Federal Fluminense. ${ }^{3}$ Departamento de Psicologia, Ufes. 


\section{Introdução}

A Política Nacional de Humanização (PNH) do Sistema Único de Saúde (SUS) chega ao seu quinto ano, momento em que podemos identificar importantes acúmulos, assim como a necessidade de ampliarmos o debate junto aos pesquisadores da área. Entendida não como programa, mas como política que atravessa as diferentes ações e instâncias gestoras do SUS, a PNH aposta na indissociabilidade entre os modos de produzir saúde e os modos de gerir os processos de trabalho, entre atenção e gestão, entre clínica e política, entre produção de saúde e produção de subjetividade. Tem por objetivo provocar inovações nas práticas gerenciais e nas práticas de produção de saúde, propondo, para os diferentes coletivos/equipes implicados nestas práticas, o desafio de superar limites e experimentar novas formas de organização dos serviços e novos modos de produção e circulação de saber e de poder. A PNH é uma política transversal que indica a inseparabilidade entre gestão e atenção (Brasil, 2008). Entende-se que a gestão dos processos de trabalho em saúde não pode ser reduzida à sua dimensão gerencial-administrativa separada das práticas de cuidado, ou seja, não pode se identificar com uma lógica gerencial marcada pelos valores de mercado (Schwartz, 2002). Apostar na inseparabilidade entre atenção e gestão é propor a transversalização destes domínios, frequentemente tomados como distintos e separados (de um lado as práticas de cuidado e, de outro, as de gestão). Superar essa dicotomia é defender a dupla interferência que altera tanto as práticas de cuidado a partir da problematização do seu processo de trabalho, quanto modifica os modelos de gestão, impondo aí a atitude analítica e de cuidado com os sujeitos implicados no trabalho em saúde: trabalhadores e usuários dos serviços de saúde. Gerir e cuidar tornam-se, assim, aspectos complementares. O cuidador cuida e gere seu processo de trabalho do mesmo modo que o gestor também não está dispensado da tarefa de cuidar. A gestão perde, portanto, o aspecto que tradicionalmente a associa ao autoritarismo, hierarquia e imposição de regras, que se destinam a normatizar previamente, ao máximo possível, os processos de trabalho, em sintonia com práticas hierarquizantes e de dominação.

A direção proposta, então, é outra: enfatizar as dimensões dos processos do trabalho que afirmam valores do bem comum (Schwartz, 2002). Valores que escapam de qualquer tentativa de quantificaçãomensuração e que privilegiam uma relação singular e histórica com o trabalho a partir do que se efetiva localmente nos ambientes laborais. Não se trata, portanto, da gestão, mas de uma gestão, já que não está em uma coisa, nem pertence a coisa alguma, não depende de um objeto nem pertence a um sujeito. Do ponto de vista da $\mathrm{PNH}$, os modos de gestão dos serviços são tomados como pura imanência, pois estão em todas as partes, em todos os momentos, é um processo de singularização que se atualiza nos sujeitos e nas maneiras como se organiza um serviço de saúde. Consequentemente, gerir não se identifica com um conjunto de normas exteriores àqueles que constroem cotidianamente os serviços, mas se desprende deles e, ao mesmo tempo, os incorpora; uma vez que está na imanência do território de forças moventes em que se funda uma organização e não se reduz à estratificação dura dos regulamentos e aos modelos dos planejamentos idealizados. O processo de gerir é tomado como arte das multiplicidades, que difere do gerenciar, uma vez que se coloca como organização própria do múltiplo e que se orienta pelas questões "quanto", "como" e "em que caso" determinada realidade se produz e se institui (Deleuze, 2006, p.260).

Assim, gerir um serviço, na direção definida pela $\mathrm{PNH}$, implica considerar que se faz gestão de processos mais do que de coisas, se acompanha os movimentos de institucionalização de dada organização, e que se avalia a dinâmica das forças instituintes em constante contraste com as formas instituídas. E, nas organizações, as coisas com que a gestão está às voltas são encarnações de idéias, sendo, portanto, inseparáveis de um potencial, de uma virtualidade, não implicando qualquer identidade prévia de que se possa dizer do uno e do mesmo (Barros, Fonseca, 2008). Gestão como lugar de passagens e de conexões, que se constitui a partir da dessubstancialização do lugar do gestor, não está na sala do diretor ou da coordenação de um estabelecimento de saúde, mas considerada como conector de processos de subjetivação e de relações de poder. Gerir é negociar, é debater normas, regras, valores. É inventar modos de fazer. É inventar uma cadência. Juntos com Deleuze e Guattari (1997, p.40), diríamos que quando procuramos "singularidades" de uma matéria ou de um material, sem a preocupação de descobrir uma forma, somos forçados a seguir, nos engajando "na variação contínua das variáveis, em vez de extrair delas constantes". 
Trabalhar-gerir, portanto, inclui a criação de formas-subjetividades à deriva - trabalhadores que, no curso da atividade e na relação com os instrumentos de trabalho, criam permanentemente, reinventando-se, incessantemente, como trabalhadores; é "prática de tateio" (Kastrup, 1999). Os modos de operar nos serviços se confundem com o próprio processo de criação de si. Processos de subjetivação-modo de gestão-produção de saúde.

Com este entendimento, a PNH busca fomentar, nos atores que constroem os processos de trabalhorede, o exercício de suas condições como protagonistas de análises compartilhadas e intervenções nos espaços de trabalho. Objetiva-se, assim: superar posturas legalistas e assistencialistas, fomentar o envolvimento dos trabalhadores na construção de projetos, incentivando a multiplicação de diferentes movimentos e rodas, fortalecendo as redes, colocando em análise o sucateamento e a precarização do processo de trabalho em saúde, o quadro atual do financiamento da Saúde Pública no Brasil.

Nessa direção, compreende-se que os processos de trabalho se constituem como espaços concretos de invenção e reinvenção de regras e usos de si (Schwartz, 2003), e a gestão como função de quem está produzindo e conduzindo seu próprio fazer. Aqui se coloca um método: conduzir análises e intervenções com/nos espaços de trabalho, de forma a traçar um caminho no sentido da inclusão dos diferentes agentes implicados nos processos de trabalho-gestão. Um método que inclui gerência e trabalhadores no sentido da produção de autonomia, protagonismo e corresponsabilidade.

A discussão da PNH nos vários espaços do SUS tem revelado sua força, traduzida em diferentes dimensões: de reposicionamento dos sujeitos na perspectiva de seu protagonismo, autonomia e corresponsabilidade; da potência do coletivo; da importância da construção de redes de cuidados compartilhados, em contraste com o mundo contemporâneo caracterizado pelo individualismo e pela competição que transforma a agonística do campo social em antagonismos. A força da PNH vem, então, apontar para o compromisso com uma posição ético-estético-política no campo da Saúde. Ética porque implica mudança de atitudes dos usuários, dos gestores e trabalhadores de saúde, de forma a comprometê-los como corresponsáveis pela qualidade das ações e serviços gerados; estética por se tratar do processo de produção/criação da saúde e de subjetividades autônomas e protagonistas; política, porque diz respeito à organização social e institucional das práticas de atenção e gestão na rede do SUS.

No contexto contemporâneo, somos convocados a manter vivo o movimento constituinte do SUS quando nos confrontamos com as forças de privatização da saúde. Este é o momento da mobilização de universidades e de centros de pesquisa em defesa da Política Pública de Saúde. A humanização das práticas de atenção e gestão do SUS é uma das frentes que aposta no fortalecimento e consolidação da democratização das práticas de produção de saúde.

A PNH afirma seus princípios e diretrizes apostando no SUS que dá certo. Tal aposta retoma a força constituinte do movimento 'susista' que, na elaboração da Constituição Federal em 1988, afirmou a saúde como direito e dever, como valor universal e distribuído equanimente, como sentido integral. Com os princípios do SUS temos, entre nós brasileiros, um compromisso que nos une, pois eis que o sentido de "único" ganha toda a sua complexidade. Não se trata apenas de afirmar a unidade de um sistemaum sistema único de saúde -, mas também um sistema que nos une ou que pode e deve servir como causa comum: o comum que nos permite a comunicação, a comunidade de interesses e compromissos e a comunhão de sentidos. Reativar este comum é, para a $\mathrm{PNH}$, estabelecer um conjunto de princípios e diretrizes metodológicos que indicam um modo de fazer ou um modo de realizar a aposta do SUS.

Por princípio entendemos o que causa ou dispara movimentos de mudança das práticas de produção de saúde. Nessa perspectiva, são princípios metodológicos da PNH: 1) a transversalidade, entendida como aumento do grau de abertura comunicacional intra e intergrupos; 2) a inseparabilidade entre atenção e gestão; 3) o protagonismo dos sujeitos e coletivos.

Se há movimento, temos de definir, consequentemente, diretrizes que façam valer o sentido comum da mudança nas práticas de produção de saúde. Daí a PNH propor como diretrizes: a ampliação da clínica; a cogestão e a participação; os direitos dos usuários; a valorização do trabalho e do trabalhador; o acolhimento; a ambiência; o fomento das redes. Enfim, o SUS que dá certo é aquele que se afirma como prática contra-hegemônica aos processos de sucateamento da vida, de recusa aos processos de precarização do trabalho, de enfrentamento às práticas de tutela de trabalhadores e usuários, afirmando o direito a uma vida que difere e fabrica um comum. Trata-se de dar destaque, fazer referência explícita aos direitos dos usuários e dos trabalhadores de saúde, potencializando a 
capacidade de criação que constitui o humano, valorizando sua autonomia numa configuração coletiva dos processos de atenção e gestão. A PNH ganha a dimensão de política pública porque é transversal às demais ações e programas de saúde e porque atenta ao que, como movimento e rede social, dialoga e tensiona com suas proposições.

De 2000 a 2002, o Programa Nacional de Humanização da Atenção Hospitalar (PNHAH) iniciou ações em hospitais com o intuito de criar comitês de humanização voltados para a melhoria na qualidade da atenção ao usuário e, mais tarde, ao trabalhador.

Em 2003, intensifica-se esta aposta e o tema da Humanização da Atenção e Gestão do SUS ganha nova inflexão: deixa de estar limitado a programas que incluem vários projetos importantes, tais como o "Parto Humanizado" e o "Humanização da Atenção Hospitalar". A proposta da PNH foi a de se constituir como política que atravessa os diferentes setores e programas do Ministério da Saúde (MS), buscando traçar um plano comum e transversal por meio da valorização da dimensão humana das práticas de saúde.

No início de 2003, o Ministério da Saúde decidiu fazer uma aposta na humanização como reencantamento do SUS. Ainda que, timidamente, este tema já se anunciava desde a XI Conferência Nacional de Saúde, intitulada "Acesso, qualidade e humanização na atenção à saúde com controle social" (Brasil, 2000).

Completamos, em 2008, cinco anos de construção da PNH. Em 2003, esta política nascia na Secretaria Executiva do Ministério da Saúde (MS) com a tarefa de fomentar a transversalidade. O SUS, como processo de mudança dos modelos de atenção e de gestão das práticas de saúde, exige que os diferentes sujeitos nele implicados se mobilizem em uma ação coletiva. Para realizar esta ação coletiva, seria necessário alterar o padrão de comunicação no campo da Saúde, criando interfaces, conexões, redes de comunicação. Era preciso aproximar o MS do SUS e, por isso, definia-se a seguinte proposição: a construção do Ministério Único da Saúde (MUS). Transversalizar é aumentar o grau de comunicação entre os grupos e dentro dos grupos. Partíamos daí para a construção da PNH.

A PNH nasceu dentro da máquina do Estado, gestada como uma política de governo, no entanto, sempre a quisemos como uma política pública, uma política do coletivo. A direção tomada nestes cinco anos foi fomentar o coletivo da $\mathrm{PNH}$, buscando capilarizar os princípios, as diretrizes e os dispositivos da Política. Éramos poucos e, hoje, somos muitos, mas ainda insuficientes frente ao tamanho dos desafios do SUS. Construir o HumanizaSUS como uma política pública é encarnar um modo de fazer, uma atitude de corresponsabilidade, de protagonismo e de autonomia na realidade concreta dos trabalhadores e usuários de saúde.

Cinco anos ainda é pouco, embora não queiramos envelhecer. O SUS nos exige o esforço de renovar, de nos renovarmos. Melhor do que envelhecer é o HumanizaSUS poder se dissolver como política de governo para se tornar um modo de fazer corporificado nos trabalhadores e usuários.

\section{Humanização: entre uma moral piedosa e uma ética da alteridade}

O conceito de humanização é polissêmico, comportando diversos enunciados e é permeado por imprecisões. Os modos de abordar/compreender humanização não se dissociam das propostas/práticas de humanização. Deste modo, as diversas enunciações constituem distintas práticas de gestão e de modelos de atenção, que nem sempre coincidem. Dentre os sentidos comumente utilizados, quando discutimos com profissionais de saúde e usuários, encontram-se aqueles que designam humanização como: tratar com respeito e carinho, amor, empatia, capacidade de colocar-se no lugar do outro, acolhimento, aceitação do outro, diálogo, tolerância, tratar do outro com respeito e educação, aceitar as diferenças, resgatar a dimensão humana nas práticas de saúde. Outros sentidos também são evocados, tais como: acolhimento resolutivo, participação no SUS, corresponsabilidade, inclusão, controle social, ética, não discriminação, transformar o SUS, valorização do trabalhador, dentre outros.

No que se refere à produção acadêmica, a polissemia se mantém e o termo humanização é abordado numa pluralidade de sentidos. Contudo, permanecem majoritários na produção acadêmica alguns sentidos de humanização que agrupamos de acordo com os eixos indicados a seguir.

Um eixo que compreende a humanização como vínculo entre profissionais e usuários, efetuado a partir de ações pautadas na compreensão e valorização dos sujeitos. Nesse eixo podemos, ainda, 
abarcar os sentidos que compreendem a humanização como atitude ética e humanitária, que se constitui a partir de uma escuta sensível e compreensiva e uma ação ética. Nestas acepções a humanização circunscreve-se, prioritariamente, no domínio das relações interpessoais. Entende-se, também, que o desenvolvimento das tecnologias no âmbito da saúde acarreta a desumanização das práticas neste campo, e que a ética é uma escolha racional entre possibilidades existentes.

Num segundo eixo, a humanização é associada à qualidade do cuidado, que incluiria a valorização dos trabalhadores, e ao reconhecimento dos direitos dos usuários. Neste eixo, as ações de humanização dizem respeito: às melhorias na estrutura física dos serviços de saúde; à presença do acompanhante nas consultas e internação; à capacitação/formação dos profissionais de saúde; às ações pontuais dirigidas aos trabalhadores, tais como atividades comemorativas; à contratação de maior número de profissionais, entre outras.

Cabe ressaltar, que, mesmo se apresentando em menor número, algumas produções acadêmicas sinalizam que a humanização do SUS envolve: condições de trabalho, modelo de assistência, formação permanente dos profissionais de saúde, direitos dos usuários, avaliação do processo de trabalho. Boa parte das produções acadêmicas, publicadas após 2004, ainda estabelecem interlocução com o PNHAHMS, criado em 2001 e extinto em 2003.

Como desafios aos processos de humanização do SUS, algumas produções como as de Gallo, Reis e Mazarina (2004), Deslandes (2004) e Hennington (2008) sinalizam para sua construção como política pública, ou seja, que não se restrinja a uma política governamental que sofre os efeitos de descontinuidade tão recorrentes em função do rodízio de governantes. Outro desafio diz respeito à interlocução com as instituições de formação, objetivando interferir na organização curricular dos cursos de graduação e pós-graduação em saúde, de modo a ampliar a compreensão dos formandos acerca dos modelos de gestão e atenção à saúde. Por fim, ações que interfiram nas práticas de gestão - ainda verticalizadas e autoritárias -, na saúde dos trabalhadores, e nas práticas cotidianas de assistência.

No panorama destes desafios indicados pelos autores citados, mas também corroborada por gestores e demais profissionais de saúde, a formação dos profissionais é aludida como estratégia privilegiada para que se promova a alteração das práticas de saúde. Porém esse é um desafio que se depara com a permanência de ações de formação, pautadas, conforme alerta Teixeira (2005), por um viés transmissivista e doutrinário.

O que se pode perceber é que os processos de gestão em sua conexão com os modos de cuidar pouco são tomados como um desafio na humanização do SUS, permanecendo na saúde a compreensão de gestão associada a um posto (gerência), a um sujeito (gestor) e aos espaços formalizados de gestão (conselhos, comissões, dentre outros). Entendemos, como já indicado, que gestão é criação de normas (Schwartz, 2002), regulação do processo de trabalho, operada por todos aqueles envolvidos no processo de produção de saúde.

No que se refere à humanização das práticas em saúde, grande parte das produções acadêmicas e das ações de formação se situa, também, sobretudo, em um polo subjetivo nomeado como dimensão ética e que compreenderia os vínculos entre profissionais e usuários, ou seja, a esfera configurada como relacional (Schraiber, 1997). Humanização é aí entendida como esfera subjetiva de relações entre sujeitos idealizados e, portanto, abstratos. Neste sentido, a ética é reduzida ao plano intersubjetivo/ interpessoal, privado-íntimo, divorciando-a do plano da política que produz modos de existência.

Do nosso ponto de vista, outro desafio no tocante à humanização do SUS, conforme já assinalamos, é afirmar um exercício ético que se faz por um método de tríplice inclusão: dos sujeitos, dos coletivos e dos analisadores sociais expressos nas crises e perturbações que o encontro com a alteridade, com aquilo que há de estranho em nós, nos desloca das posições nas quais tecemos nossa existência. O que se busca afirmar aqui é uma ética da alteridade que não se faz apartada do mundo em que criamos e convivemos. A aposta consiste em deslocar a humanização do campo de uma moral que faz escolhas entre o bem e o mal, ao acentuar os processos de produção de subjetividades. Assim, os vínculos entre sujeitos não se efetuam fora do plano das práticas de cuidado e dos processos de gestão.

Conforme Campos (2007, p.11), "A humanização formulada pela PNH é uma estratégia política que tem funcionado 'como um dispositivo valioso', na medida em que amplia a agenda para a política de saúde no Brasil". O autor destaca a PNH como uma política que vai na "contramão de práticas tecnocráticas e estratégias que se efetivam por meio de portarias e regulações de diferentes ordens". 
Além disso, assinala que a PNH parte das experiências vividas no chão dos serviços de saúde, em sentido contrário da tradição verticalista e autoritária, muito comum no âmbito da saúde pública.

Assim, a PNH enfrenta o desafio de atribuir um outro sentido ao termo humanização, vocábulo polissêmico e polêmico, certamente. Que sentidos são atribuídos ao vocábulo? Qual sentido a PNH atribui a essa palavra que delimita um campo problemático, um modo de trabalhar e que se expressa no esforço de formulação de uma política pública, o que não se faz sem essa disputa de sentidos?

A PNH não pretende ter o monopólio e a exclusividade de imprimir à palavra humanização o sentido verdadeiro, mas, apenas, construir mais um deles. Busca redimensionar um modo naturalizado de concepção do humano e abrir possibilidades para o debate sobre esta questão, que tem sido tema sempre que se trazem, para a conversa: as mazelas dos serviços, a fragilidade da rede de atenção, a lotação dos hospitais, o descaso com a população, a suposta irresponsabilidade dos profissionais de saúde.

Como indicamos, a partir de uma rápida visada no que tem sido produzido no campo da Saúde Coletiva, muitas são as concepções de humanização que tentam expressar as situações adversas encontradas nos serviços prestados aos cidadãos. A PNH colocou para si um outro desafio: quebrar a cristalização desse conceito, de maneira a deixar aparecer seus pontos dissonantes e surpreendentes. Um conceito é sempre singular e só pode ganhar terreno variando-se, bifurcando-se, metamorfoseando-se, de forma a dar conta dos movimentos incessantes do que parece imóvel. Os enunciados que são produzidos em torno do conceito de humanização da saúde não são imediatamente visíveis, mas ao mesmo tempo invisíveis e não ocultos. Esses enunciados não são imediatamente perceptíveis, já que estão encobertos por palavras e por silêncios, pelas práticas discursivas e não discursivas; e por modos de fazer nem sempre explicitados. Por isso, para tomarmos os sentidos do conceito de humanização é preciso buscar o enunciado, "é preciso descobrir o seu pedestal, poli-lo, e mesmo moldá-lo, inventá-lo" (Deleuze, 2005, p.27).

Tal esforço de polimento conceitual tenta mostrar o vazio entre os diferentes sentidos de dado conceito, sua múltipla enunciação, e não a essência do vocábulo ou encontrar seu verdadeiro sentido, usando-o de forma generalizada. Polimento que se destina a permitir a construção de outros sentidos para o verbo humanizar, evitando que a inflação de seu uso ponha a perder seu valor de intervenção e se transforme em um conceito que tudo explica. Buscar seu transbordamento de sentidos é dar visibilidade a esse patrimônio, a esse retrabalho (Durrive, Schwartz, 2007) do conceito consoante com as expectativas de cada trabalhador do SUS. Retrabalho significa debate de normas, fazendo emergir outros sentidos para esse vocábulo, uma vez que fora desse debate temos imposição de sentidos, dominação. Dar visibilidade a esse debate é afirmar o plano comum que atravessa as diferentes práticas que revitalizam o SUS, o que não pode ser feito do exterior, fora do campo onde esta questão emerge, sem a inclusão dos diferentes atores que operam e constroem o SUS. Enfrentar este debate significa, portanto, afirmar a radicalidade da humanização do SUS como obra aberta, que recusa a totalização de um único sentido de humanização, ao mesmo tempo em que problematiza os efeitos destes mesmos sentidos nas práticas efetuadas no âmbito da saúde.

Um conceito, portanto, se expressa no modo como o utilizamos. Espera-se, assim, que a produção do conceito de humanização seja capaz de responder ao apelo de problemas reais com os quais nos deparamos nos serviços de saúde.

A construção de um sentido possível para a expressão Humanização da Saúde se expressa na PNH em um novo posicionamento que afirma um homem comum (com artigo indefinido), um ser humano na sua existência concreta, na sua diversidade normativa e nas mudanças que experimenta nos movimentos coletivos. Aqui se produz uma inflexão importante, uma vez que esse outro modo de colocar o problema da humanização na saúde implica a produção de outras formas de relação entre os sujeitos que constroem os cotidianos dos estabelecimentos de saúde; sujeitos concretos e engajados nas práticas locais onde são capazes de transformar os processos de trabalho e se transformarem nesse processo. Humanizar, portanto, não para encontrar o 'bom humano' ou o 'humano ideal', mas para fazer conexão com as forças do coletivo, sem o qual não se faz política pública.

Partindo destes princípios e deste conjunto de questões, foi que consideramos a necessidade de se construir um dispositivo que pudesse colocar na roda os diversos modos de fazer o SUS, nem sempre consoantes. Então, a estratégia desse dispositivo foi a proposição de um seminário: "Humanização do 
SUS em debate". O Seminário, realizado no município de Vila Velha (ES), reuniu diferentes setores envolvidos com as políticas públicas brasileiras neste ano de 2009 em que comemoramos os vinte anos do SUS. A construção desse Seminário foi pautada na responsabilidade ético-política de fazer desse encontro um momento de reflexão-crítica-invenção de caminhos para alguns dos impasses vividos no SUS, de publicização dos confrontos e crises no processo de construção das políticas públicas de saúde e de formação.

\section{Um modo de fazer seminário}

O Seminário de Vila Velha (ES) teve como idéia e desejo promover um amplo debate sobre a Humanização do SUS. O diálogo aciona mudanças, altera, acolhe e incorpora novos elementos na construção de uma política pública. Nos cinco anos de existência da $\mathrm{PNH}$, permaneceu a convicção de que não se constrói, bem como não se fortalece uma política pública sem inclusão de sujeitos, sujeitos no plural, sujeitos no singular. Incluir não pode ser um discurso da moda e o desafio é a sua afirmação como uma prática política. Em outras palavras: nestes cinco anos alteraram-se, no tempo, as motivações, mas permaneceu irremovível, como opção política e como método, incluir sujeitos e travar diálogos. Assim, esse Seminário se colocou como uma estratégia para reunir um conjunto relativamente amplo de pesquisadores e docentes cujas produções têm tomado por preocupação pensar e afirmar mudanças no SUS na perspectiva de consolidá-lo como política pública inclusiva, solidária e de qualidade.

O SUS é um instrumento de luta, no campo da Saúde, às formas de autoritarismo e às práticas de captura da vida no capitalismo contemporâneo. Levar à frente tal luta pela democratização institucional das práticas de produção de saúde exige o compromisso dos diferentes atores envolvidos neste processo. Daí a importância de colocarmos lado a lado trabalhadores, gestores e usuários nos momentos de planejamento, execução e avaliação das práticas de saúde. É preciso, no entanto, ampliar esta roda, incluindo aqueles que participam da formação dos trabalhadores do SUS. Neste sentido, é importante priorizar também os processo de formação e a construção coletiva de discussão acerca do conceito de humanização junto às instituições de ensino superior e centros de pesquisa no campo da Saúde.

O processo de formação é compreendido como modo de interferir nas práticas cotidianas dos serviços, nos processos de trabalho, nos modos de gerir e cuidar, de forma a potencializar os princípios do SUS. Com os processos de formação, pode-se enfrentar e desmontar a separação formação-trabalho, ao se considerar que os processos de trabalho se constituem como matéria-prima dos processos de formação. Por outro lado, o investimento na formação dos profissionais de saúde e redes sociais é uma posição de aposta na invenção de outras práticas. Por considerar a formação como aquilo que se dá como experiência singular-coletiva, produção de sujeitos que se querem protagonistas de sua história e de políticas públicas, é que entendemos fundamental estabelecer o compromisso com a consolidação de modos de fazer e de pensar políticas de saúde de maneira crítica e desnaturalizadora de problemas, aí incluído o próprio conceito de humanização do SUS.

Em 2006 e 2007, as apostas da PNH nos processos de formação focalizaram, prioritariamente, a educação permanente em serviço dos trabalhadores da saúde. Com o Seminário de Vila Velha, ampliouse a confiança nos processos de formação, agora visando à interface com profissionais que atuam na formação dos trabalhadores do SUS, todos eles responsáveis pela produção de conhecimento na área e pela formação dos acadêmicos no campo da Saúde.

O Seminário "Humanização do SUS em debate" organizou-se fazendo uma aposta metodológica, pois teve o sentido de Roda de Conversação. A Roda remete à criação contínua, ao que perece para ser reinventado. Símbolo do movimento que necessita sempre de conexões para se efetuar, a roda nos lembra que a vida é obra aberta. O momento da roda é o momento da troca, da pactuação, do compartilhamento das experiências, do comum e do diverso. A roda rodando nos convoca a driblar/ desviar as hierarquias e os lugares que ocupamos nas relações de saber-poder. Daí a afirmação do modo de fazer da PNH pautado pelo método da inclusão. Ao mesmo tempo, esse evento propôs a desespetacularização do evento acadêmico por meio da prática da lateralização do debate. Os participantes estiveram lado a lado, fazendo rodar a palavra em um espaço sem lugares privilegiados, sem mesas, sem púlpitos. Diferentes pesquisadores do país reuniram-se numa roda de discussão em torno de quatro eixos: 1) Princípios do SUS e a humanização das práticas de saúde; 2) Humanização e 
organização dos serviços e práticas de saúde; 3) Redes de produção de saúde e humanização; 4) Biopolítica, produção de saúde e um outro humanismo.

Cada um desses eixos norteou uma roda de debate em sessões de quatro horas, contando com 150 participantes (pesquisadores convidados e consultores da $\mathrm{PNH}$ ). O modo de operar proposto para as discussões procurou escapar dos formatos tradicionais de seminários acadêmicos, criando funçõesdebate diferenciadas (mas não hierarquizadas) para atiçar o movimento da roda. Assim, a dinâmica dessa roda contou com seis funções:

a. pesquisadores e consultores da PNH que qualificavam o debate, considerando a diversidade do campo da Saúde Pública;

b. propositores que tiveram como função problematizar as práticas da saúde com base no tema da humanização do SUS;

c. debatedores que tomaram as proposições feitas como oportunidade de ampliação do debate para a efetivação da humanização do SUS;

d. observadores analistas que realizaram, em cada eixo, a cartografia das linhas de composição do debate, destacando os desafios enfrentados e os avanços indicados na problematização do tema-eixo;

e. moderador que teve a função de mediar o debate, apontando os pontos de interseção e as linhas de desvio, viabilizando a emergência de novas proposições;

f. coordenadores que garantiam a circulação da palavra.

Para a formulação das proposições, foram convidados pesquisadores que têm tomado as temáticas propostas nos eixos em seus trabalhos no campo da Saúde, aos quais foi solicitado o envio prévio de um texto em sua primeira versão, que foi disponibilizado aos demais participantes do Seminário e apresentado na roda de debates objetivando disparar as proposições iniciais. Contudo, por entender que todos os participantes do Seminário constituíam-se como propositores na Roda de Conversação, todos foram convocados a posicionar-se frente aos eixos estruturantes do Seminário, integrando a roda para qualificar o debate. Ainda que os participantes tivessem diferentes implicações nessa roda, a partir desta diferença, esperava-se a corresponsabilização de todos na produção do debate. Convidamos, para cada eixo do Seminário, pesquisadores que estariam comprometidos em disparar as proposições iniciais. Neste contexto, para a função de debatedores, foram convidados consultores da PNH que elaboraram, junto com o coletivo da PNH, textos para discussão da proposição feita para cada tema-eixo.

Assim, os temas propostos para o debate expressavam os inúmeros desafios com os quais os trabalhadores e usuários dos serviços de saúde e os pesquisadores desse campo vêm se deparando ao longo desses vinte anos de construção do SUS. Lidar com tais desafios implica, do ponto de vista da PNH, a criação de um modo de fazer afirmado no âmbito dessa política como o método da tríplice inclusão: dos sujeitos, dos coletivos e dos tensionamentos. Os eixos que nortearam o debate expressam a aposta da PNH no reencantamento do SUS. Logo, a idéia do Seminário foi, concomitantemente, expandir os graus de comunicação entre os atores estratégicos no campo da formação.

Ressaltamos que, no ano em que comemoramos os vinte anos do SUS, quando enfrentamos desafios como o da crise de financiamento, é importante reunirmos os diferentes setores envolvidos com as políticas públicas brasileiras. O SUS, no cenário contemporâneo, não pode se furtar ao confronto com as forças de privatização da saúde. Sendo assim, este é o momento da mobilização das universidades e dos centros de pesquisa em defesa da Política Pública de Saúde. A humanização das práticas de atenção e gestão do SUS é uma das frentes de fortalecimento e consolidação da democratização das práticas de produção de saúde.

Esta foi a provocação: construir um dispositivo-seminário consoante com esta direção ético-política em que o método de inclusão foi reafirmado, na medida em que se buscava incluir o que coloca em questão a humanização do SUS e, também, a própria PNH, como um dos enunciadores de uma política de humanização do SUS. Reafirmamos que é, no tensionamento de posições político-conceituais, que uma política pública pode se fortalecer constituindo-se como uma política do comum.

Nesta direção, o método proposto no Seminário mostrou-se potente no sentido de promover a lateralização da comunicação e o tensionamento de posições acerca dos desafios atuais do SUS. O que se buscava não era, simplesmente, o embate de posições antagônicas, mas, sobretudo, alimentar uma agonística que não se sustenta com base em desqualificações de posições contrárias. O que atravessava o processo de discussão eram os desafios do SUS que temos nas mãos e para, com eles, tecermos uma 
${ }^{4}$ Lançamos mão aqui da indicação de observadoras-analistas que, ao analisarem os movimentos das discussões no decorrer do seminário, referiramse às alusões a times $\mathrm{e}$ torcidas feitas por participantes no momento inicial de apresentação. política do comum, embora em diversos momentos os lugares instituídos buscassem se reafirmar em times e torcidas ${ }^{4}$ adversárias.

O que esse dispositivo-seminário acionou? Um dispositivo se destina a produzir movimentos, deslocando processos naturalizados, colocando em análise as condições de emergência de concepções já reafirmadas no campo da Saúde Pública. A avaliação do Seminário "Humanização do SUS em debate" nos indica que sua eficácia residiu menos nos seus produtos resultantes e muito mais nos processos que disparou: seja na ampliação dos graus de transversalidade, no fortalecimento e ampliação de redes, seja no retrabalho do conceito de humanização em sua potência e risco, indicando uma possível inflexão nos modos de produzir humanização nos serviços saúde.

O seminário-dispositivo-intervenção se destinou a fortalecer um SUS que dá certo e, portanto, deseja uma saúde impiedosa que afirma uma vida que varia, não teme a diferença e se faz como obra aberta. O reencantamento do SUS só se faz tecendo uma política do comum que não se efetua por meio de uma homogeneização de conceitos e perspectivas ou da confraternização de posições diferentes, mas se constitui entre o singular e o coletivo.

A aposta do Seminário, entre outras já apontadas neste texto, foi a de que a potência das lutas que tece cotidianamente o SUS, desde sua criação, inspirasse as discussões e análises, de modo que a memória dessas lutas fortaleça nossa aposta em um outro humanismo, aquele que se tece entre o comum e o diverso na afirmação da reexistência como obra aberta.

\section{Colaboradores}

Os autores trabalharam juntos em todas as etapas de produção do manuscrito.

\section{Referências}

BARROS, M.E.B.; FONSECA, T.M.G. Gestão escolar. In: CORAZZA, S.M.; AQUINO, J.G. (Orgs.). Abecedário: educação da diferença, 2008. Obra inédita ainda não publicada.

BRASIL. Ministério da Saúde. Secretaria de Atenção à Saúde. Núcleo Técnico da Política Nacional de Humanização. HumanizaSus: documento base para gestores e trabalhadores do SUS. 4.ed. Brasília: Ministério da Saúde, 2008.

Conselho Nacional de Saúde. O Brasil falando como quer ser tratado: efetivando o SUS, acesso, qualidade e humanização na atenção à saúde com controle social. In: CONFERÊNCIA NACIONAL DE SAÚDE, 11., 2000, Brasília. Relatório final... Brasília: Ministério da Saúde, 2000. (Série Histórica do Conselho Nacional de Saúde, 2).

CAMPOS, G.W. A humanização é uma estratégia política. In: BARROS, M.E.B.; SANTOS-FILHO, S.B. (Orgs.). Trabalhador da saúde: muito prazer! Protagonismo dos trabalhadores na gestão do trabalho em saúde. ljuí: Unijuí, 2007. p.11-5.

DELEUZE, G. Diferença e repetição. Rio de Janeiro: Graal, 2006.

Foucault. São Paulo: Edições 70, 2005.

DELEUZE, G.; GUATTARI, F. Devir-intenso, devir-animal, devir-imperceptível. In: (Orgs.). Mil platôs: capitalismo e esquizofrenia. São Paulo: Editora 34, 1997. p.1 $\overline{1-114}$.

DESLANDES, S.F. Análise do discurso oficial sobre a humanização da assistência hospitalar. Cienc. Saude Colet., v.19, n.1, p.7-14, 2004.

DURRIVE, L.; SCHWARTZ, Y. (Orgs.). Trabalho e ergologia: conversas sobre a atividade humana. Niterói: EDUFF, 2007. 
GALLO, P.R.; REIS, A.O.; MAZARINA, I.V. A humanização na saúde como instância libertadora. Saude Soc., v.13, n.3, p.36-43, 2004.

HENNINGTON, E.A. Gestão dos processos de trabalho e humanização em saúde: reflexões a partir da ergologia. Rev. Saude Publica, v.42, n.3, p.555-61, 2008.

KASTRUP, V. A invenção de si e do mundo: uma introdução do tempo e do coletivo no estudo da cognição. Campinas: Papirus, 1999.

SCHRAIBER, L. No encontro da técnica com a ética: o exercício de julgar e decidir no cotidiano do trabalho em Medicina. Interface - Comunic., Saúde Educ., v.1, n.1, p.123-40, 1997.

SCHWARTZ, Y. A abordagem ergológica do trabalho e sua contribuição para a pesquisa em administração. In: SEMINÁRIO INTERNACIONAL DE ADMINISTRAÇÃO, 2003, Vitória. Comunicação oral... Vitória: UFES, 2003.

Disciplina epistêmica, disciplina ergológica: paidéia e politéia. Pro-posições, v.13, n.1, p.126-49, 2002.

TEIXEIRA, R.R. Humanização e atenção primária à saúde. Cienc. Saude Colet., v.10, n.3, p.585-97, 2005.

HECKERT, A.L.C.; PASSOS, E.; BARROS, M.E.B. Un seminario dispositivos la humanización del Sistema Único de Salud (SUS) en debate. Interface - Comunic., Saude, Educ., v.13, supl.1, p.493-502, 2009.

El artículo discute el proceso de construcción del Seminario "Humanización del SUS en Debate" indicando su conexión con los desafíos actuales del SUS y con las proposiciones de la Política Nacional de Humanización (PNH). Presenta los principios y directrices de la Política Nacional de Humanización del SUS (PNH) y su proceso de construcción, discutiendo los diferentes sentidos del término humanización. Se indica por fin la apuesta metodológica del seminario que trató de promover un amplio debate sobre la Humanización del SUS por medio de conversaciones conjuntas que objetivaron la interfaz con profesionales que actúan en la formación de los trabajadores del SUS, responsables por la producción de conocimiento en el área de la salud y por la formación de los académicos en este campo.

Palabras clave: Humanización de la atención. Salud. Formación. Sistema Único de Salud.

Recebido em 14/01/09. Aprovado em 11/05/09. 